Bond University

Research Repository

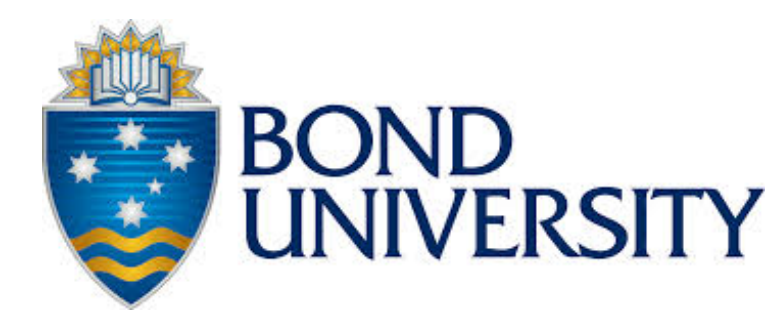

\title{
Emotional intelligence and optimistic cognitive style in certainty in career decision making
}

Alexander, Victoria; Bartrum, Dee; Hicks, Richard E.

Published in:

Global Science and Technology Forum (GSTF) Journal of Psychology

DOI:

$10.5176 / 2345-7872 \_1.2 .15$

Licence:

CC BY-NC

Link to output in Bond University research repository.

Recommended citation(APA):

Alexander, V., Bartrum, D., \& Hicks, R. E. (2014). Emotional intelligence and optimistic cognitive style in certainty in career decision making. Global Science and Technology Forum (GSTF) Journal of Psychology, 1(2), 22-26. https://doi.org/10.5176/2345-7872_1.2.15

\section{General rights}

Copyright and moral rights for the publications made accessible in the public portal are retained by the authors and/or other copyright owners and it is a condition of accessing publications that users recognise and abide by the legal requirements associated with these rights.

For more information, or if you believe that this document breaches copyright, please contact the Bond University research repository coordinator 


\section{Bond University}

\section{ePublications@bond}

Faculty of Society and Design Publications

Faculty of Society and Design

$10-1-2014$

\section{Emotional intelligence and optimistic cognitive style in certainty in career decision making}

Victoria Alexander

Bond University,Victoria_Alexander@bond.edu.au

Dee Bartrum

NSW Health

Richard Hicks

Bond University, Richard_Hicks@bond.edu.au

Follow this and additional works at: http://epublications.bond.edu.au/fsd_papers

Part of the Cognitive Psychology Commons

Recommended Citation

Victoria Alexander, Dee Bartrum, and Richard Hicks. (2014) "Emotional intelligence and optimistic cognitive style in certainty in career decision making" GSTF Journal of Psychology, 1 (2), 22-26: ISSN 2345-7872.

http://epublications.bond.edu.au/fsd_papers/86

This Journal Article is brought to you by the Faculty of Society and Design at ePublications@bond. It has been accepted for inclusion in Faculty of Society and Design Publications by an authorized administrator of ePublications@bond. For more information, please contact Bond University's

Repository Coordinator. 


\title{
Emotional Intelligence and Optimistic Cognitive Style in Certainty in Career Decision Making
}

\author{
Victoria E. Alexander (Bond University), Dee A. Bartrum (NSW Health), and Richard E. Hicks (Bond \\ University)
}

\begin{abstract}
The current study tested whether Trait Emotional Intelligence variables and Optimistic Cognitive Style together predicted feelings of certainty in career decision making. Few studies have examined the effects of trait emotional intelligence or life style orientation on career choice, and no study has been found that combined both the life orientation (optimism) and the trait emotional intelligence domains and facets: this current study examined the relative weights of these facets and lifestyle orientation in relation to career certainty. Participants were from a convenience sample of 142 university students who completed a paper-and-pencil survey containing the following measures: the Life Orientation Test-Revised (assessing optimism, the Trait Emotional Intelligence Scale (TEIQue), and the Career Decision Scale (CDS).

It was found that optimism and the four main domains (of wellbeing, self-control, emotionality, and sociability) and several of the subscales of the TEIQue correlated significantly with career certainty. A unique significant predictor of Career Certainty was found to be Stability-Impulsivity (a facet in the Self-Control domain of the TEIQue) but optimism was not a factor in predicting career certainty when the stabilityimpulsiveness factor was accounted for. Self-control- stability (low impulsiveness) predicted career certainty. It would seem that stability in thinking and action helps career commitment (certainty). Implications are drawn for career development counselling and suggestions made for future research.
\end{abstract}

Keywords-Trait emotional intelligence; cognitive style; career decision-making; career certainty

\section{INTRODUCTION}

Career commitment (certainty) requires self-understanding, understanding of the 'world of work', stability in choice, and awareness of one's own values. Positive career certainty is associated with resilience and resourcefulness [1, 2, 3, 4]. But to what extent are the factors of positive life orientation (optimism) and levels of trait emotional intelligence facets contributors to that commitment and certainty? This study examined the relative inputs in a study of 142 university students in Australia, and reports on the results.

Career certainty involves ability to decide and commit, whereas career indecision involves inability in the same areas $[5,6]$. Such decision making ability is related to the identity achievement and identity diffusion stages in Marcia's theory of career development [7].

Career indecision is defined as the inability to decide and commit to a career or vocation that one wants to pursue [6]. Research in this field has estimated that the level of career indecision amongst university students is as high as 50\% [8] The ability to decide on a career is important, especially for university students as it can affect the direction of study as well as the vocational path after completing education [9]. The current study aimed to examine some of the more prominent personality variables in the literature: that is cognitive style (optimism) and trait emotional intelligence in relation to career certainty.

Career decision making has been studied extensively especially among adolescents and young adults with attention to relationships with mental health and wellbeing or the reverse- depression and anxiety [4, 8, 10, 11], and social and interpersonal factors such as peer and parental attachment $[12,13,14,15]$.

Emotional intelligence is also related to attachment styles [2, 13, 14, 16], and to psychological well-being and emotions in making decisions [14, 17, 18]. Emotional wellbeing, in particular life satisfaction, was positively related to the ability to decide on a career [18]. Life satisfaction and optimism appear related and we developed a research project examining the relationship of cognitive style/ optimism (along with trait emotional intelligence facets in relation to decision making) as predictors of career decision making.

\section{A. Cognitive Style}

Cognitive style was defined for this study as optimism and operationalised by the self-report questionnaire, the Life Orientation Test- Revised (LOT-R) [19]. Optimism is defined as a generalised tendency to expect positive outcomes in life [20]. Cognitive style has been researched to some extent in relation to career decision making, with findings from one study suggesting that lower levels of optimism are associated with increased career indecision [21]. It is thought that cognitive style, in particular, optimism, is key within career development and career decision making for adolescents and adults within a university setting. One study [22] implied this also, in research investigating relationships among career self- 
efficacy, optimism and attachment styles. Accordingly the current study aimed to build upon this existing research by examining cognitive style in relation to career decision making, and in relation to emotional intelligence variables. The question was asked: Would emotional intelligence variables and optimism be related to career decision making? This current paper examined these aspects in a sample of 142 Australian university students.

\section{B. Trait Emotional Intelligence}

Trait emotional intelligence is a relatively unexplored concept in the realm of career development. In this study trait emotional intelligence was operationalised using the TEIQue [23]. There are four higher order factors (domains) of wellbeing, self-control, emotionality and sociability, as well as a global trait emotional intelligence score. In addition, there are 15 distinct facets of EI which make up the four domains and which include adaptability (flexibility in a one's approach to work and life); emotion regulation; impulsivity vs reflection and control (stability); self-motivation; empathy; assertiveness (degree of forthrightness); emotion expression (ability to communicate emotions fluently to others); relationships (ability to initiate and maintain emotional bonds); social awareness (including social skills); and happiness. Additionally, emotion perception; emotion management; selfesteem; stress management; and optimism are also seen as part of trait emotional intelligence.

Little research has been conducted to assess trait emotional intelligence in relation to career certainty. However, one study [24] found individuals with higher emotional intelligence had fewer dysfunctional thoughts. The authors indicated that this might suggest individuals with higher emotional intelligence are better able to cope with the career decision-making process. Another study [25] also found that individuals with higher emotional intelligence had fewer difficulties in the career decision making process. This research suggested that trait emotional intelligence would impact on career decision making. On the dysfunctionality that can occur in decision making, another study [26] found that persistent career decision making difficulties were related to emotional intelligence Our study aimed to explore whether trait emotional intelligence in conjunction with an optimistic life orientation are linked to certainty in career decision making.

\section{Current Study}

We decided to investigate the relationships between emotional intelligence, optimistic cognitive style, and career decision making within the sample of Australian university students.

Several hypotheses were raised for the study. On the basis of research presented, it was anticipated:

H1: That Career Certainty scores would be significantly and positively related to Trait Emotional Intelligence Scores.

In addition, to examine in more detail the Career Certainty/Emotional Intelligence relationship, and the relationship of EI together with optimism it was further hypothesized:

$\mathrm{H} 2$ : That Career Certainty scores would be significantly predicted by the combination of each of the four domains of the TEIQue scale (Well-Being, Self Control, Emotionality and Sociability), and

H3: That Career Certainty would be significantly predicted by a combination of the significantly related scales from the TEIQue with Optimistic Cognitive Style.

\section{METHOD}

\section{A. Participants}

A convenience sample of 150 participants aged 18 years and over was recruited from a university in south-eastern Queensland Australia to partake in the study (Mean Age = 23.3; $S D=6.6$ ). The sample comprised of 99 females and 43 males and mainly comprised of first year psychology students who obtained $1 \%$ credit point for their participation as part of course requirement. Participants were also obtained from the library and received a snack-size chocolate bar for completing the survey.

\section{B. Materials}

Career Decision Scale. Career indecision and career certainty were measured using the Career Decision Scale [27]. The instrument consists of 19 items with two subscales: Career Indecision, a 16 item scale which provides a measure of individuals inability to decide upon a career and the Certainty Scale, a 2 item measure of individuals level of certainty in having made a career decision. Item 19 was not included in this study. Adequate psychometric properties have been demonstrated in several studies [28]. Cronbach's alpha for the current sample was .93 for the Career Indecision and .69 for the Career Certainty subscales.

Cognitive Style. To measure levels of optimism, the revised version of the Life Orientation Test was utilized [19] The LOT-R is a 10 item scale containing four filler items and six scale items. Adequate psychometric properties exist [19]. Internal consistency for our sample was .64.

Trait Emotional Intelligence. The facets of trait emotional intelligence were measured using the Trait Emotional Intelligence Questionnaire [23] which contains 153 items. Adequate psychometrics have been demonstrated [29] with preliminary evidence of convergent-discriminant validity as well as criterion validity. In our study, internal reliabilities for the subscales ranged from .64 to .86 .

\section{Procedure}

Participants were provided with a brief verbal statement and a written explanatory statement about the purpose of the study, expectations of participants and the reason career indecision is an important area of research. The survey took participants on average 45 minutes to complete. The data was de-identified and confidential, with only the researchers viewing the data. No participants withdrew from the study. Participants returned the survey in a sealed envelope to the researcher or placed it in a secure drop-box. 


\section{RESULTS}

\section{Preliminary Analysis}

Data were screened for missing values, outliers, and required statistical assumption. Of 150 respondent profile sheets, eight were deficient and were removed, leaving a total of 142 respondent profiles for consideration in the data analyses.

Initial bivariate correlation coefficients were calculated for all variables studied, yielding coefficients between career certainty and all fifteen emotional intelligence variables at highly significant levels (.29 to .64). Similarly career certainty and the LOT-R optimism correlation was highly significant (.29).

Hypothesis 1, that Career Certainty scores would be significantly predicted by the four domains of the TEIQue EI scale (Well-being, Self Control, Emotionality and Sociability) was partially supported. The results are shown in Table 1. The results demonstrated that the four domain variables significantly accounted for $15 \%$ (Adjusted $R^{2}=.13$ ) of the variance, $F(4,137)=6.20, p<.001$ in Career Certainty. Inspection of the regression coefficients demonstrated that Self Control $(\beta=.13, t=.21 p=.03)$ and Emotionality $(\beta$ $=.15, t=2.55, p<.01)$ were significant predictors of Career Certainty; whereas Well-being and Sociability were not significant predictors when the contributions from SelfControl and Emotionality were taken into account

The subscales that comprised of the significant domains of Self Control and Emotionality were then entered into a regression to see whether they would predict Career Indecision.

TABLE I. PREDICTING CAREER CERTAINTY FROM THE FOUR DOMAINS OF THE TRAIT EMOTIONAL INTELLIGENCE QUESTIONAIRE (TEIQUE): REGRESSION ANALYSIS

\begin{tabular}{|l|c|c|c|c|}
\hline \multicolumn{1}{|c|}{ Variable } & $B$ & $S E B$ & $B$ & $p$ \\
\hline Well Being & -.05 & .04 & -.14 & .22 \\
\hline Self Control & -.08 & .032 & -.22 & .01 \\
\hline Emotionality & -.08 & .032 & -.29 & .01 \\
\hline Sociability & -.00 & .032 & -.01 & .95 \\
\hline Total $\mathrm{R}^{2}$ & .32 & & & .00 \\
\hline
\end{tabular}

Hypothesis 2, that Career Certainty scores would be significantly predicted by the subscales found to be significant from the four domains of the TEIQue scale was partially supported. The results are shown in Table II. The results demonstrated that the seven variables which made up the two domains significantly accounted for $22 \%$ (Adjusted $R^{2}=.18$ ) of the variance, $F(7,134)=5.89, p<.001$ in Career Indecision. Inspection of the regression coefficients demonstrated that Impulsivity (Low) $(\beta=.55, t=3.45, p<.05)$ were significant predictors of Career Certainty; whereas Emotion Regulation, Stress Management, Emotion Perception, Emotion Expression, Empathy and Relationships were not significant predictors when the contributions from Impulsivity (Low) were taken into account.

TABLE II. PREDICTING CAREER CERTAINTY FROM THE SEVEN SUBSCALES OF THE SELF CONTROL AND EMOTIONALITY DOMAINS OF THE TEIQUE

\begin{tabular}{|l|c|c|c|c|}
\hline \multicolumn{1}{|c|}{ Variable } & $B$ & $S E B$ & $B$ & $p$ \\
\hline SelfCControl: Emotion Regulation & -.19 & -.10 & -.80 & .43 \\
\hline SelfCControl: Stress Management & .99 & .23 & .05 & .66 \\
\hline Self-Control: Impulsivity (Low) & .55 & .16 & .32 & .00 \\
\hline Emotionality: Emotion Perception & .30 & .22 & .16 & .17 \\
\hline Emotionality: Emotion Expression & .26 & .15 & .18 & .08 \\
\hline Emotionality: Empathy & .07 & .20 & .04 & .74 \\
\hline Emotionality: Empathy & .07 & .20 & .04 & .74 \\
\hline Emotionality: Relationships $^{\text {Total } \mathrm{R}^{2}}$ & -.16 & .18 & -.09 & .38 \\
\hline & .47 & & & .00 \\
\hline
\end{tabular}

Hypothesis 3, that Career Certainty would be significantly predicted by a combination of the significantly related scales from the TEIQue and Optimistic Cognitive Style, was partially supported. The results are shown in Table III. The results demonstrated that the two variables accounted for $17 \%$ (Adjusted $R^{2}=.16$ ) of the variance, $F(2,136)=$ 14.37, $p<.001$ in Career Certainty. Inspection of the regression coefficients demonstrated that Impulsivity (Low) $(\beta$ $=.60, t=4.60, p<.01)$ was a significant predictor of Career Certainty; whereas Optimistic Cognitive style was not when the contributions from Impulsivity (Low) were taken into account

TABLE III. PREDICTING CAREER CERTAINTY FROM IMPULSIVITY (LOW) AND OPTIMISM AS PREDICTOR VARIABLES: REGRESSION ANALYSIS

\begin{tabular}{|l|l|l|l|l|}
\hline Variable & $B$ & $S E B$ & $\beta$ & $p$ \\
\hline Impulsivity (Low) & .60 & .13 & .36 & .00 \\
\hline Optimism & .11 & .06 & .15 & .06 \\
\hline Total R & .17 & & & .00 \\
\hline
\end{tabular}

\section{DISCUSSION}

The main aim of the study was to investigate Optimistic Cognitive Style and Emotional Intelligence domains and facets, in relation to Career Certainty in decision making.

Hypotheses 1 and 2 were partially supported, with the self-control and emotionality domains of the TEIQue predicting career certainty. The facets of low impulsivity, and emotion expression were the more significant predictors of career certainty. In general emotional intelligence has been seen as being related to decision making efficacy [14, 25, 26].

The final hypothesis was partially supported, with only impulsivity significantly predicting career certainty when both optimism and impulsivity were included in the analyses. 
The current study supported the findings (with career certainty being seen as directly related to career decision making) indicating that the fifteen emotional intelligence traits, as well as optimistic life orientation, were all directly related to career certainty. However, it was impulsivenessstability among these variable facets that carried considerable weight in influencing career certainty. Not everyone and not all young people determining on career choice are 'stable' or maintain attitudes of reflection and control in their decision making. Being 'impulsive' would mean that decisions may be based on insufficient and inadequate information. The implication for career advisers and career counsellors is that this aspect of emotional intelligence may need to be identified first in their clients and developed as needed. Such development of skills (skills training) would emphasise how to make decisions and solve problems- following step by step procedures. Decision making skills can be learned and provision of and guidance over the use of materials that build such skills is needed.

In addition to the stability-impulsiveness factor in career certainty our results also showed that among the EI facets, both self-regulation of emotions generally and positive expression of emotions (communication) were related to career choice confirmation or certainty. However, stabilityimpulsiveness was the strongest contributor.

The current research was especially interested in the contribution of cognitive style or optimistic outlook as a predictor of career certainty, including whether optimism would combine with emotional intelligence facets in a complementary way. In the final analysis this meant whether optimism would add substantially to the contribution made by stability-impulsiveness in predicting career certainty. Optimism had previously been identified as correlating with career certainty [21] or likely to be linked to career decision making,[22]. We found indeed that optimism scores were significantly and positively related to career certainty $(r=.29)$ and also to emotional intelligence variables $(r=.29$ to .64$)$. However, when the EI facets were included in a regression equation with optimism the EI facet of stability-impulsiveness was a significant contributor to career certainty but cognitive style- optimism was not. While optimism may be important in other aspects in careers (e.g., career satisfaction and relationships with colleagues at work) it was not a significant factor in predicting career choice certainty in our current sample.

In conclusion to help individuals in their career decision making, regardless of their personality outlook or cognitive style- optimism, they must first be helped to develop their own emotional skills and approaches and be helped to avoid the consequences of 'Impulsiveness'. Learning decision controls and developing stability in gaining information before making decisions clearly can lead to more effective career decision making and feelings of confidence and certainty on the career choice made [24].

\section{A. Summary, Limitations and Future Research}

A convenience sample of university students was used; consequently, results may not generalize to other populations. However, the findings of the study present a potential insight into the relationship between optimism (cognitive style) and emotional intelligence in relation to career certainty. The study demonstrates that there are meaningful relationships between the variables which should be investigated in future research. Life Orientation (Optimism) was found to be significantly related to Career Certainty. Also, however, two domains of emotional intelligence were found to be significantly related to career decision making (certainty): these were self-control and emotionality. When these domains were examined in detail (through the seven facets involved) only low impulsivity (or stability and control) as a trait was a significant predictor, though emotion expression (the ability to be aware of and to express clearly one's own feelings) was also a strong though non-significant predictor in this sample. Interestingly when Impulsiveness and Optimism were entered as predictor variables in the regression to predict career certainty, Optimism was no longer a significant contributor. The Self-Control Domain (through its low Impulsiveness facet) was sufficient to explain the relationship. Further study of the role of life orientation and emotional intelligence as a whole and through its facets would be of interest.

\section{REFERENCES}

[1] V. Alexander, R.E. Hicks, and D. Bartrum, "Resilience and resourcefulness in dealing with uncertainty in life commitment: Career choice as a case example," in M. J. Celinski \& K. M. Gow (Eds.), Continuity versus creative response to challenge: The primacy of resilience and resourcefulness in life and therapy, 2011, New York, NY: Nova Science Press.

[2] D. Bartrum, V. Alexander, and R. Hicks, "Emotional intelligence, peer attachment and career indecision" In the Proceedings of the Third Annual International Conference on Cognitive and Behavioural Psychology, held Singapore 24-25 February 2014; pp. 145-149.

[3] D. Brown, "Career information, career counselling, and career development" (9th Ed.). Boston: Pearson/Allyn \& Bacon, 2007.

[4] J. Page, M.A. Bruch, and R.F. Hasse, "Role of perfectionism and fivefactor model traits in career indecision," Personality and Individual Differences, vol. 45, pp. 811-815, 2008.

[5] M.R. Durr, and T.J.G. Tracey, "Relation of person-environment fit to career certainty," Journal of Vocational Behavior, vol. 75, pp. 129-138, 2009.

[6] F. Guay, C Senecal, L. Gauthier, and C. Fernet, "Predicting career indecision: A self-determination theory perspective," Journal of Counselling Psychology, vol. 50, pp. 165-167, 2003.

[7] J.E. Marcia, "The ego identity status approach to ego identity". In J. E. Marcia, A. S. Waterman, D. R. Matteson, S. L. Archer, \& J. L. Orlofsky (Eds.), Ego identity: A handbook for psychosocial research (pp. 1-21). New York: Springer-Verlag, 1993.

[8] D.M. Tokar, J.R. Withrow, R.J. Hall, and B. Moradi "Psychological separation, attachment security, vocational self-concept crystallization and career indecision: A structual equation analysis," Journal of Counsulting Psychology, vol. 50, pp. 3-19, 2003.

[9] A. Guerra, and J.M. Braungart-Ricker," Predicting career indecision in college students: The roles of identity formation and parental relationship factors," Career Development Quarterly, vol. 47, pp. 255 266, 1999. 
[10] C.G. Campagna, and G.J. Curtis, "So worried I don't know what I want to be: Anxiety is associated with increased indecision and reduced career certainty," Journal of Guidance and Counselling, vol. 17, pp. 91-96, 2007.

[11] W. Patton, D.A. Bartrum, and P. Creed, "Gender differences for optimism, self esteem, expectations and goals in predicting career planning and exploration in adults," International Journal for Educational and Vocational Guidance, vol. 4, pp. 193-209, 2004.

[12] G.C. Armsden, and M.T. Greenberg, "The inventory of Parent and Peer Attachment: Individual differences and their relationship to psychological well-being in adolescence," Journal of Youth and Adolescence, vol. 16, pp.427-453, 2009.

[13] R.E. Hicks, and V. Alexander, "Peer attachment and career indecision," Journal of Counselling Psychology, vol. 12, pp. 10-18, 2012.

[14] I. Gati, R. Gadassi, N. Saka, Y. Hadadi, N. Ansenberg, R. Friedman, and L. Asulin-Peretz, "Emotional and personality-related aspects of career decision-making difficulties: Facets of career indecisiveness," Journal of Career Assessment, vol. 19, pp. 3-20, 2011.

[15] J.B. Wolfe, and N.E Betz, "The relationship of attachment variables to career decision making self-efficacy and fear of commitment," The Career Development Quarterly, vol. 52, pp. 362-379, 2004.

[16] E. Hamarta, M. Deniz, M, and N. Saltali, "Attachment styles as a predictor of emotional intelligence," Educational Sciences: Theory \& Practice, vol. 9, pp. 213-229, 2009.

[17] N. Sevdalis, K.V. Petrides, and N. Harvey, "Trait emotional intelligence and decision related emotions," Personality and Individual Differences vol. 42, pp. 1347-1358, 2007.

[18] M. Zhou, and X. Yabo, 'University students' career choice and emotional well-being," Journal of Educational and Social Research, vol. 3, pp. 243-248, 2013.

[19] M.F. Scheier, C.S. Carver, and M.W. Bridges, "Distinguishing optimism from neuroticism (and trait anxiety, self-mastery, and self-esteem): A reevaluation of the Life Orientation Test," Journal of Personality and Social Psychology, vol. 6, pp. 1063-1078, 1994.

[20] M.F. Scheier, and C.S. Carver, "On the power of positive thinking: The benefits of being optimistic," Current Directions in Psychological Science, vol. 2, pp .26-30, 1993.

[21] P. A, Creed W. Patton, and D. Bartrum, "Internal and external barriers, cognitive style, and the career development variables of focus and indecision," Journal of Career Development, vol. 30, pp. 277-294, 2004.

[22] A.E. Moon, "Examining attachment styles and optimism in a moderator model," Unpublished doctoral thesis, Commonwealth University, Virginia.

[23] K.V. Petrides, and A.D. Furnham, "Trait emotional intelligence: Behavioral validation in two studies of emotion recognition and reactivity to mood induction," European Journal of Personality, vol. 17, pp. 39-57, 2003.

[24] A.D. Dahl, R.K. Austin, B.D. Wagner, and A. Lukas, "The relationship between negative Career thoughts \& emotional intelligence," The Canadian Journal of Career Development, vol. 7, pp. 4-10, 2008.

[25] A. Di Fabio, and L. Palazzeschi, "Emotional intelligence personality traits and career decision difficulties," International Journal for Eductational and Vocational Guidance, vol. 9, pp. 135,146, 2009.

[26] N. Saka, and I. Gati, "Emotional and personality-related aspects of persistent career decision-making difficulties," Journal of Vocational Behavior, vol. 71, pp. 340-358, 2007.

[27] S.H. Osipow, "Manual for the Career Decision Scale. (Rev. Ed.) Odessa, FL: Psychological Assessment Resources (1987).

[28] M.L. Sweeney, and T.R. Schill, "The association between self-defeating personality characteristics, career indecision, and vocational identity," Journal of Career Assessment, vol. 6, pp. 69-81, 1998.

[29] M. Mikolajczak, O. Luminet, C. Leroy, and E. Roy, "Psychometric properties of the trait emotional intelligence questionnaire: Factor structure, reliability, construct, and incremental validity in a Frenchspeaking population," Journal of Personality Assessment, vol. 88, pp. 338-353, 2007.

\section{AUTHORS' PROFILE}

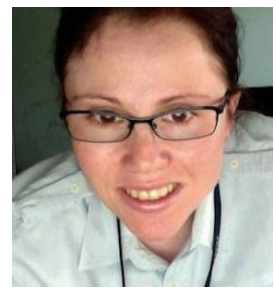

Victoria Alexander received her BSS (Psych) Honours from Bond University and is currently tutor and doctoral student in the School of Psychology at Bond University. Her research interests include career studies, perfectionism and assessment.

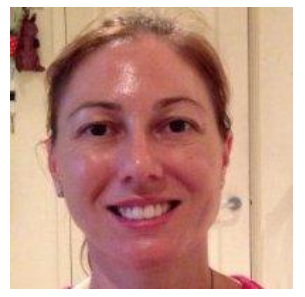

Dee A Bartrum is a Clinical Psychologist /Care Coordinator for NSW Health in the child and adolescent inpatient unit Lismore, NSW. She has held several academic and professional appointments since graduating $\mathrm{PhD}$ in Psychology from Griffith University Australia, including as Assistant Professor in Psychology and Psychology Clinic Director at Bond University.

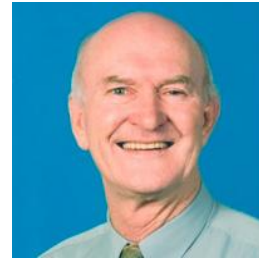

Richard E Hicks is Professor of Psychology at Bond University with research interests in occupational, clinical and counseling psychology. His academic and professional background includes appointments in Australia, Africa (in Zambia) and Papua New Guinea, and sabbaticals in the UK and the USA. 